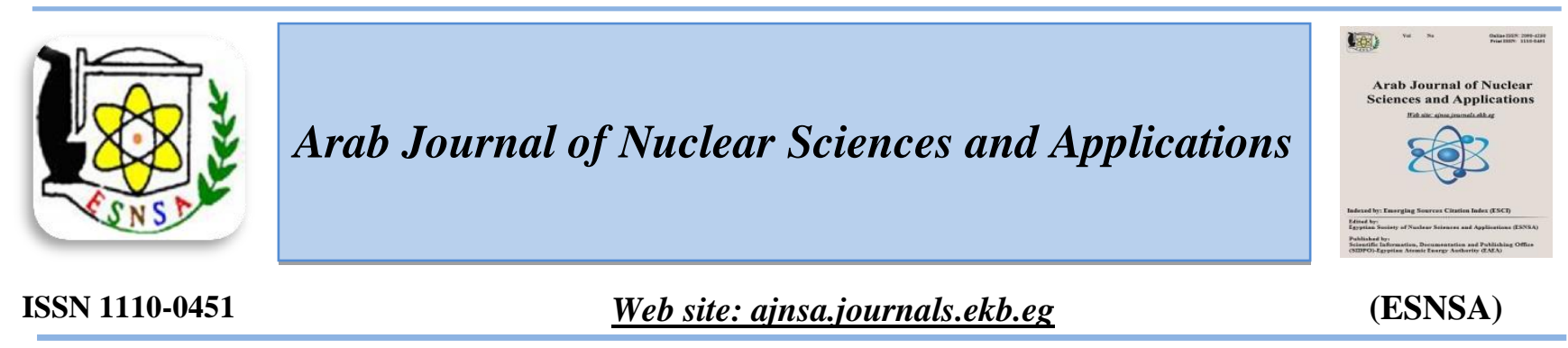

\title{
A comparative Study Between the Exposures of 6MeV Photons and 0.3 mT-50 Hz Magnetic Fields in Rat's Liver
}

\author{
Mai. I. El-kaliuoby \\ Physics \& Chemistry Department, Faculty of Education, Alexandria University, Alexandria, Egypt
}

Received $16^{\text {th }}$ Dec 2018 Effect of $0.3 \mathrm{mT}-50 \mathrm{~Hz}$ magnetic field exposure on rats' liver dielectric relaxation was studied. Animals Accepted $26^{\mathrm{h}}$ May 2019 were exposed, similar to occupational workers, to 8h/day for periods from 1 to 4 weeks. The exposure effects were monitored relative to the effect of exposure to high energy $6 \mathrm{MeV}$ standard dose of 1 rad. Dielectric relaxations in frequency, up to $8 \mathrm{MHz}$, were carried out immediately for all animals from each group to examine bioelectrical changes in liver relative permittivity, conductivity, and dielectric loss. The results indicated a significant difference in the dielectric characteristics due to the counter-ion diffusion at frequencies up to $1 \mathrm{MHz}$, whereas increasing the frequency results in an unremarkable shift. The data revealed that the relative fraction of damage (RFD)is remarkable damage due to magnetic fields in a manner that it should not be less important than high energy photons. Significantly, animals of 1 week magnetic field exposure showed a maximum damage effect by $15 \%, 26 \%$ and $5 \%$ damage in relative permittivity, conductivity and dielectric loss respectively more than $6 \mathrm{MeV}$ photons exposure. To further characterize damages and speculating possible effects in liver tissue, the enzymatic levels of serum glutamic oxaloacetic transaminases (SGOT), serum glutamic pyruvic transaminases (SGPT), total protein (TP) content, and Malondialdehyde (MDA) were monitored. In the same trend, the enzymatic levels recorded an abnormal increase attributed to the hepatic structural changes and tissue injury. In comparison to the unexposed group, the samples from 1-week magnetic field exposure confirmed liver bioimpedance results and indicated a significant increase in the enzymatic levels by $20.6 \%, 17.1 \%$, $3.32 \%$ and $13.1 \%$ for SGOT, SGPT, TP and MDA respectively. The former results may reflect the animal body self-adaptation as exposure period increased. It is worthy to mention that this work is an important one that correlates between the effects of both extremely low frequency fields and ionizing radiation.

Keywords: Magnetic field, Photons, Liver, Dielectric, Liver enzymes, RFD

\section{Introduction}

Humans are exposed to the natural magnetic field produced in the earth's molten core and to electric field from thunderstorm activity in the atmosphere. The biological effects of electromagnetic fields have not been demonstrated to play any major physiological role except for bird orientation and navigation and bacterial geotactic responses. Due to the wide use of electricity an artificial electric and magnetic field become apart of our living environments which are present in both residential and work place environment [1]. Due to the complexity of the biological system, however, the results of different studies are quite variable and the mechanisms of action are still poorly defined [2-4]. Electric fields in addition to magnetic fields are known to exert influence on biological systems causing actual interference to the normal functions of the organism [5-7]. The main effect of exposure to EMF is its ability to penetrate the human body and interact with ions on all organs, causing significant alterations in cell membrane potential and ionic dipolar orientations [8, 9, 10]. Magnetic fields were noticed to influence enzyme action, signal transduction, protein synthesis and gene expression. These influences may regulate cell growth and alter

Corresponding author: mai.ismail@alexu.edu.eg

DOI: 10.21608/ajnsa.2019.4242.1099

(C) Scientific Information, Documentation and Publishing Office (SIDPO)-EAEA 
its metabolic processes [11]. Recently, constantly exposure to magnetic fields illuminated remarkable structural changes in hepatocytes, primarily in the mitochondria and also split cell membrane under electron microscope [12, 13]. On the other hand, several authors suggested that biochemical and biophysical processes at the atomic level are the bases of reactions between biomolecules in an EMF, since the field can magnetically affect the chemical bonds between adjacent atoms with consequent production of free radicals $(14,15,16)$. A considerable area would be better known if information on magnetic field effects on membrane structure is measured by physical parameters namely; electrical characteristics as impedance Z, dielectric parameter $(\dot{\varepsilon})$ and conductivity $(\sigma)$. The physical mechanism for the effects of weak electromagnetic field ranging from microwave to radio waves had been discussed [17, 18 ] by the dielectric nature of all biological molecules especially those constituting the biological membrane. On the contrary, the high energy photons show clearly the effects and interpreted the modes of interactions with biological systems and specific standards are defined for exposure to such types of radiations. Therefore, the main objective of the present study is to evaluate the hazards associated with the exposures to magnetic fields $(0.3 \mathrm{mT}-50 \mathrm{~Hz})$ relative to $1 \mathrm{rad}$ dose of high energy photons $6 \mathrm{MeV}$. Liver, as one of the main vital systems to human life, was chosen to be a biomarker for the evaluation of the associated hazardous effects. This was achieved through measurements of liver dielectric characteristics in addition to its enzymatic levels in relation to exposure to a standard dose of $1 \mathrm{rad} 6 \mathrm{MeV}$ photons.

\section{Materials and Methods}

In the present work, 60 male albino rats are used, each of average weight $170 \pm 15 \mathrm{~g}$, and divided into sub groups ten rats for each group A, B, C, D, E and F. Animals of all groups were housed in normal environmental conditions and the temperature inside the lab varied between $23-25^{\circ} \mathrm{C}$. Lighting conditions depend on natural light from large windows during the day and complete darkness during the night. Animals of group A are used as unexposed group (control group) and did not receive any treatment. Animals in groups B, C, D and E are exposed to a magnetic field $(0.3 \mathrm{mT}-50 \mathrm{~Hz})$ for a period of 1 week, 2 weeks, 3 weeks and 4 weeks respectively for $8 \mathrm{~h} /$ day. At the end of the exposure period for each group, they were immediately sacrificed. Animals of group $\mathrm{F}$ are exposed to high energy photons $(6 \mathrm{MeV})$ at a dose of 1rad, emitted from a linear accelerator (LINAC) at the Faculty of Medicine, Alexandria University. The animals were placed where the LINAC's output measurements were made to ensure the correct output factor for energy $(6 \mathrm{MeV})$. It was measured collimator and couch angles were adjusted to be $0^{0}$ and (source to surface distance) $\mathrm{SSD}=100 \mathrm{~cm}$ and were immediately sacrificed after exposure. The magnetic field exposure system is present in the Laboratory of Radiation Physics at the Faculty of science, Alexandria University [19]. This system has been locally manufactured. The cylindrical body is $100 \mathrm{~cm}$ long and $60 \mathrm{~cm}$ wide and the exposure unit contains four solenoids of 48 turns; length of coils is $63 \mathrm{~cm}$. These solenoids produce a homogeneous magnetic field in the central axis, using a sinusoidal current of $50 \mathrm{~Hz}$. The rats were placed in plastic cages whose dimensions were $30 \times 40 \times 35 \mathrm{~cm}^{3}$ on a shelf inside the central axis of the solenoid to be exposed to a magnetic field as shown in Fig. (1). The magnetic field system is connected in series with the power supply and ammeter reading is fixed at $0.8 \mathrm{~A}$. To get rid of the electric field, the two ends of the cylinder are connected with wire then connected to the ground. For more precautions, an electric timer is used to adjust the exposure times especially when the electrical current decreases.

After sacrificing animals, liver tissues were immediately excised and placed between a pair of 1 $\mathrm{cm}$ diameter black platinum circular electrodes for dielectric measurements. The sample between the electrodes was maintained at a constant pressure and the distance between the electrodes was measured through the use of micrometer. While each tissue was filling the whole volume between the electrodes during measurements, the sample between the electrodes was kept at a constant temperature of $24 \pm 0.1{ }^{\circ} \mathrm{C}$. The capacitance (C) of the tissue was measured at each frequency and the resistance $(\mathrm{R})$ was recorded each run and repeated three times. The electrical impedance of each excised sample is measured between $42 \mathrm{~Hz}$ and $8 \mathrm{MHz}$ using the two electrodes technique. Samples were inserted in the capacitor cell. A micrometer was used to measure the thickness of the tissue to determine the distance between the platinum black electrodes. To facilitate measurements, a computer-controlled automatic scanning and data recording were performed with an impedance LCR meter. The relative permittivity $(\dot{\varepsilon})$, dielectric loss $\varepsilon^{\prime \prime}$, and conductivity $(\sigma)$ of the samples were calculated characteristic relaxation curves were performed. 

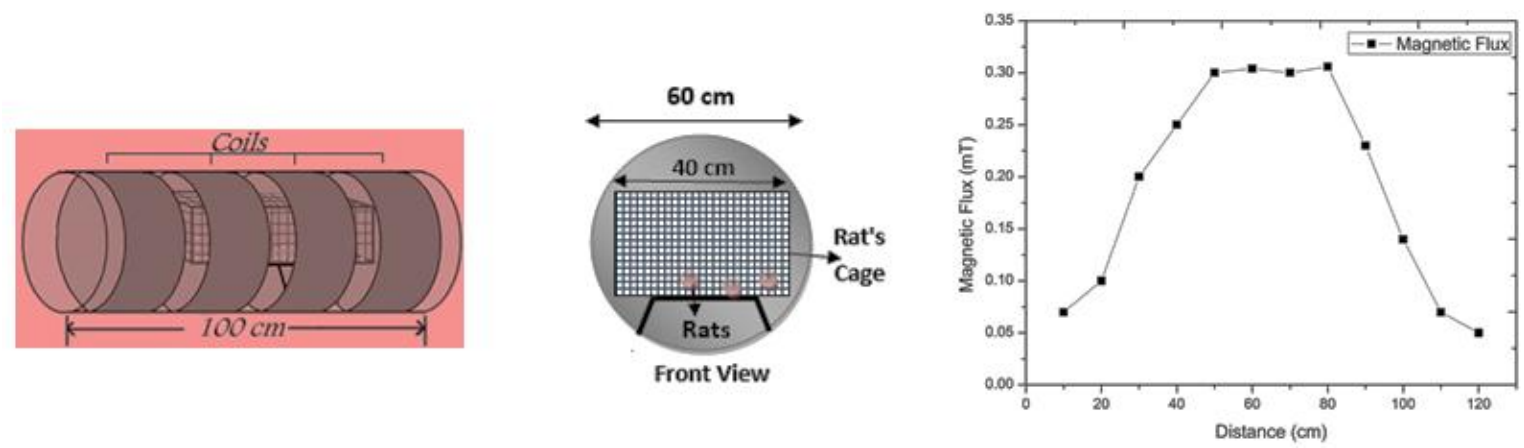

Fig. (1): Schematic diagram for magnetic exposure system and average magnetic flux density $(\mathrm{mT})$ at the center of the coil as a function of distance $(\mathrm{cm})$ supplied by current equals to $0.8 \mathrm{~A}[19]$

Biochemical parameters were measured on the same day that the material was collected. Liver glutamic oxaloacetic transaminases (SGOT) and glutamic pyruvic transaminases (SGPT) were determined using the method adapted by Fischbach and Zawta [20]. The total protein (TP) content was determined using the method adapted by Henery [21], and Malondialdehyde (MDA) protein levels of the tissue samples were determined by biuret method, and the results were given as nmol $\mathrm{MDA} / \mathrm{mg}$ protein [22].

The statistical analysis was performed using the SPSS for Windows statistical package program (SPSS Inc., ver. 21). All the data are presented as mean \pm standard deviation (SD). One-way analysis of variance (ANOVA) was performed to determine the significant differences between groups. When the one-way ANOVA revealed a significant difference, post hoc Tukey test (least significant differences test) was used to determine the differences between specific means. A " $p$ " of $<0.05$ which was considered statistically significant and used for all the comparisons.

\section{Results and Discussion}

Dielectric spectra of the biological samples reveal a rich variety of dynamic processes. Achieving a better characterization and understanding of these processes is not only of an academic interest, but also of a high relevance for medical applications. Therefore, at the end of exposing liver tissues from animals of all the exposed groups beside the unexposed one are collected and prepared for dielectric measurements the dielectric parameters of liver (electrical conductivity, dielectric loss and relative permittivity) were measured as a function of frequency. In addition, biochemical enzymatic characteristics of the liver samples were measured and relative biological changes, due to exposure of magnetic fields, were calculated relative to irradiation of a specific dose of $1 \mathrm{rad}-6 \mathrm{MeV}$ photons.

For all the prepared samples of each group, dielectric parameters were plotted versus frequency to obtain its relaxation curves. The conductivity values of different tissues were calculated at the ends of frequency range ( $1 \mathrm{MHz}$ and $8 \mathrm{MHz}$ ) for a comparison between different groups. It is worthy to mention that the conductivity, dielectric loss and relative permittivity curves for tissues, collected from all groups, showed the same dispersion at the same frequency range. Additionally, in the same manner, the dielectric relaxation reflects a broad distribution of relaxation times which arises principally from the membrane-bound macromolecule structures of the widely varying dimensions.

It was noticed that the increase in tissues conductivity with frequency is associated with a decrease in permittivity. In this regard, it is clear from the figures of all tissues from all groups that the dependence of electrical conductivity on frequency is a mirror to the relative permittivity dependence. Moreover, the dielectric permittivity and conductivity of a material are respectively the charge and current densities induced in response to an applied electric field of unit amplitude. As consequence, the electric properties of a tissue are dependent upon the structural organization of cells within the tissue and charge distribution among its cellular membrane [23]. For very low frequency range, the electric conductivity depends strongly on the volume fraction of extracellular fluid, which is expected to vary with physiological changes in the cell. On the other hand, for a frequency higher than $1 \mathrm{MHz}$ range up to $100 \mathrm{MHz}$, the cell membrane is largely shorted out and do not provide a significant barrier to current flow. Thus, the tissues can be 
considered electrically equivalent to a suspension of non-conducting proteins in electrolyte solutions and it approaches plateau up to $100 \mathrm{MHz}$. At alpha (very low frequency), dispersion is manifested by the very large increase in permittivity at audio frequency. These effects can be ascribed, at least in part, to counter-ion diffusion effects. Also, specific effects may be attributed to alpha dispersion. The charging of intra-cellular membrane-bound organelles is connected with the outer cell membrane. The beta dispersion occurs at radiofrequencies, and arises principally from the capacitive charging of cellular membranes in tissues and from dipolar orientation of tissue protein [61]. Figures (1, 2 and 3) show the relaxation curves of the liver relative permittivity conductivity, and dielectric loss respectively for samples collected from all groups. These Figures reveal a pronounced difference of liver bioimpedance for groups $\mathrm{B}$ and $\mathrm{F}$ compared to group A and a slight difference for groups C, D and $\mathrm{E}$ at low frequency range below $1 \mathrm{MHz}$ as tabulated in Table (1). Otherwise, at a high frequency, the dielectric loss and permittivity relaxation curves for all exposed groups indicate slight changes compared to the unexposed one as shown in Table (2). It presumed that at a low frequency, the significant difference may be attributed to counter-ion diffusion effects. A relative fraction of damage (RFD) in liver samples, collected from the groups exposed to MF and its attributed effects on its bioelectrical properties indicated considerable changes as listed in Table ( 3). Particularly, pronounced changes were remarkably observed for liver samples collected from animals of group B as compared to other groups $\mathrm{C}, \mathrm{D}$, and $\mathrm{E}$ up to former frequency range. The results of RFD for liver samples from group B indicated $15 \%, 26 \%$ and $5 \%$ damage in relative permittivity, conductivity and dielectric loss respectively more than group $\mathrm{F}$.

To further characterize damages and speculating possible effects in liver tissues, the enzymatic levels of SGOT, SGPT, TP content, and MDA were monitored. The SGOT is liver enzyme that aids in producing proteins and catalyzing the reductive transfer of an amino group from aspartate to $\alpha$-ketoglutarate to yield oxaloacetate and glutamate [24, 25]. Also, SGPT is a liver enzyme that plays an important role in amino acid metabolism and gluconeogenesis and catalyzes the reductive transfer of an amino group from alanine to $\alpha$-ketoglutarate to yield glutamate and pyruvate. Elevated levels of these enzymes are released during liver damage and both enzymes represent biomarkers of hepatotoxicity [26-28]. Table (4) shows the results that indicated significant increases in the enzymes levels of SGOT and SGPT for group B samples and slight increases for other groups $(\mathrm{C}, \mathrm{D}$, and $\mathrm{E})$ as compared to group $\mathrm{A}$ as shown in Figs. (4 and 5). MDH is an enzyme in the citric acid cycle that catalyzes the reversible conversion of malate into oxaloacetate utilizing $\mathrm{NAD}+$ and it is considered a periportal enzyme released into the serum indicating tissue damage. Elevations in MDH activity was found to correlate with morphological changes in liver tissues and estimating the severity of liver injury [29-31]. The estimation of total proteins in the body is helpful in differentiating between a normal and damaged liver function as the majority of plasma proteins including albumins and globulins produced in the liver. Similar to former findings, the results levels of TP and MDA indicated significant increases in its levels for group B samples and slight increases for other groups $(\mathrm{C}, \mathrm{D}$, and $\mathrm{E})$ as compared to group $\mathrm{A}$ as shown in Figs. (6 and 7). The biochemical RFD results as listed in Table (5) were in agreement to the dielectric ones which indicated the matching of liver tissue damage followed by the abnormality of enzymatic levels.
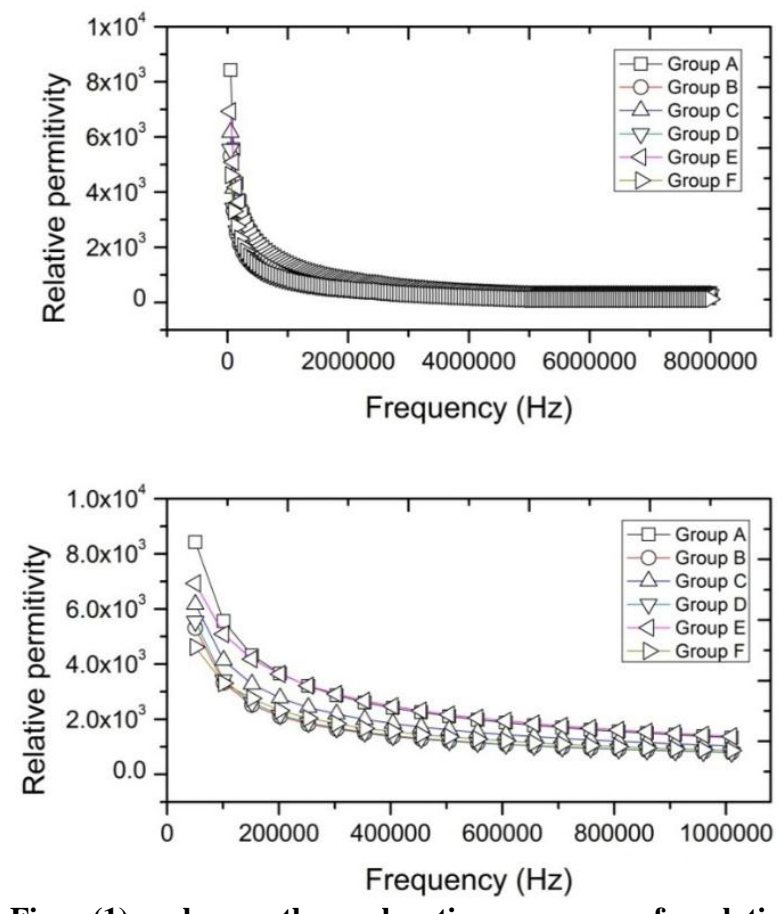

Fig. (1): shows the relaxation curves of relative permittivity for all groups 

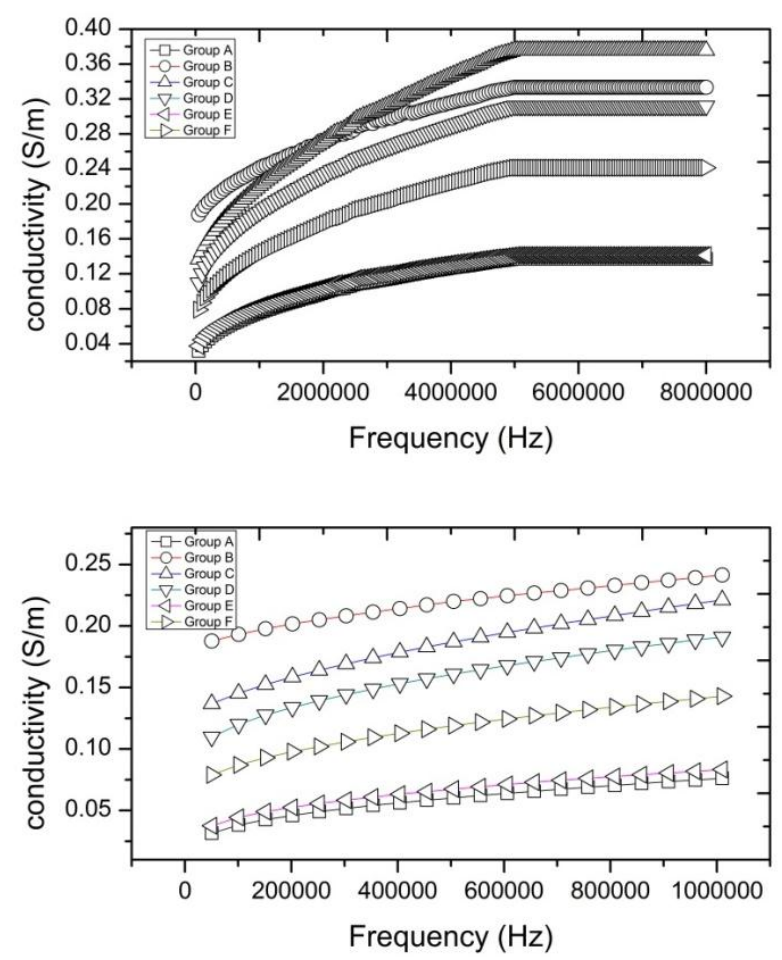

Fig. (2): the relaxation curves of conductivity for all groups
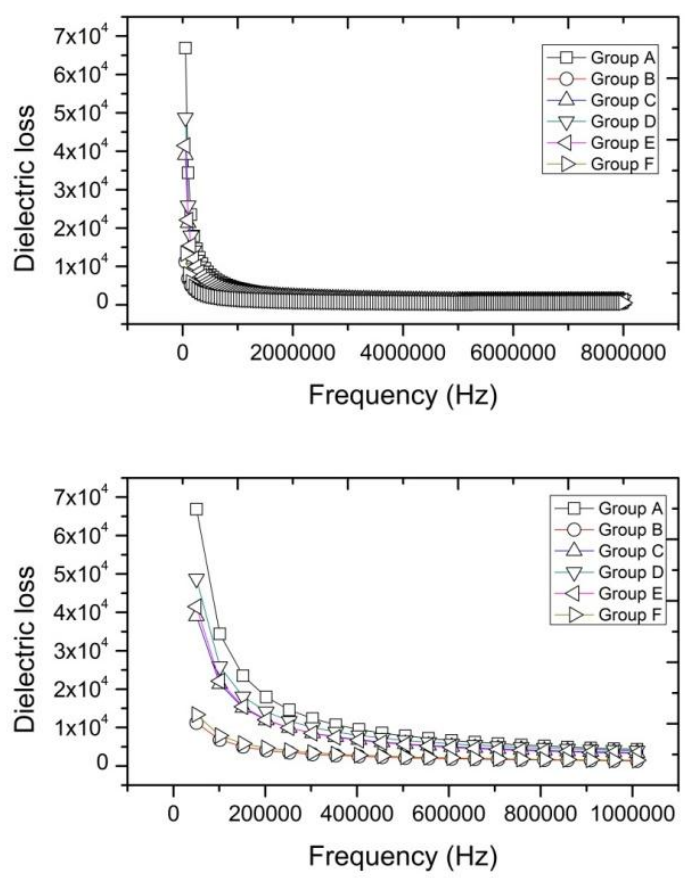

Fig. (3): the relaxation curves of dielectric loss for all groups

Table (1): A list of data for dielectric parameters at $1 \mathrm{MHz}$ for all liver samples from each group

\begin{tabular}{llll}
\hline & $\begin{array}{l}\text { Relative permittivity } \\
\text { at } 1 \mathrm{MHz} \pm \text { S.D }\end{array}$ & $\begin{array}{l}\text { Conductivity } \sigma(\mathrm{s} / \mathrm{m}) \\
\text { at } 1 \mathrm{MHz} \pm \text { S.D }\end{array}$ & $\begin{array}{l}\text { Dielectric loss } \\
\text { at } 1 \mathrm{MHz} \pm \text { S.D }\end{array}$ \\
\hline Group A & $1338 \pm 180$ & $0.142^{*} \pm 0.011$ & $4302^{*} \pm 180$ \\
Group B & $790^{*} \pm 84$ & $0.242^{* *} \pm 0.009$ & $1344 \pm 72$ \\
Group C & $1032 \pm 110$ & $0.076^{*} \pm 0.004$ & $3402^{*} \pm 110$ \\
Group D & $797^{*} \pm 36$ & $0.191^{*} \pm 0.019$ & $3942 \pm 127$ \\
Group E & $1375^{* *} \pm 214$ & $0.083 \pm 0.013$ & $3247^{*} \pm 136$ \\
Group F & $863^{*} \pm 20$ & $0.221^{* *} \pm 0.013$ & $1483^{*} \pm 89$ \\
\hline
\end{tabular}

* The difference is not significant (NS) $(\mathrm{p}>0.01)$

$* *$ The difference is significant $(\mathrm{S})(\mathrm{P}<0.05)$ 
Table (2): A list of data for dielectric parameters at $8 \mathrm{MHz}$ for all liver samples from each group

\begin{tabular}{llll}
\hline & $\begin{array}{l}\text { Relative permittivity } \\
\text { at } 8 \mathrm{MHz} \pm \text { S.D }\end{array}$ & $\begin{array}{l}\text { Conductivity } \sigma(\mathrm{s} / \mathrm{m}) \\
8 \mathrm{MHz} \pm \text { S.D }\end{array}$ & $\begin{array}{l}\text { at } \\
\text { at } 8 \mathrm{MHz} \pm \text { S.D }\end{array}$ \\
\hline Group A & $338 \pm 18$ & $0.241^{*} \pm 0.009$ & $1200^{*} \pm 130$ \\
Group B & $294^{*} \pm 14$ & $0.333^{* *} \pm 0.011$ & $482 \pm 32$ \\
Group C & $251 \pm 11$ & $0.137^{*} \pm 0.006$ & $1122^{*} \pm 180$ \\
Group D & $284^{*} \pm 16$ & $0.311^{*} \pm 0.026$ & $1351 \pm 111$ \\
Group E & $218^{* * \pm 24}$ & $0.141 \pm 0.023$ & $1039^{*} \pm 120$ \\
Group F & $123^{*} \pm 10$ & $0.375^{* *} \pm 0.006$ & $583^{*} \pm 88$ \\
\hline
\end{tabular}

* The difference is not significant (NS) ( $p>0.01)$

*** The difference is significant $(\mathrm{S})(\mathbf{P}<\mathbf{0 . 0 5})$

Table (3): A list of RFD for dielectric parameters at $1 \mathrm{MHz}$ and $8 \mathrm{MHz}$ for all liver samples

\begin{tabular}{|c|c|c|c|c|c|c|}
\hline & \multicolumn{2}{|c|}{$\begin{array}{c}\text { Relative permittivity } \\
(\Delta \dot{\varepsilon} \text {-magnetic/ } \Delta \dot{\varepsilon} \text {-photons) }\end{array}$} & \multicolumn{2}{|c|}{$\begin{array}{c}\text { Conductivity } \\
(\Delta \sigma-\text { magnetic } / \Delta \sigma-\text { photons })\end{array}$} & \multicolumn{2}{|c|}{$\begin{array}{c}\text { Dielectric loss } \\
\left(\Delta \varepsilon^{\prime \prime} \text {-magnetic } / \Delta \varepsilon^{\prime \prime} \text {-photons }\right)\end{array}$} \\
\hline & at IMHz & at $8 \mathrm{MHz}$ & at $\mathrm{IMHz}$ & at $8 \mathrm{MHz}$ & at $\mathrm{IMHz}$ & at $8 \mathrm{MHz}$ \\
\hline Group B & 1.15 & 0.20 & 1.26 & 0.69 & 1.05 & 1.16 \\
\hline Group C & 0.64 & 0.40 & 0.85 & 0.78 & 0.32 & 0.13 \\
\hline Group D & 1.14 & 0.25 & 0.61 & 0.53 & 0.13 & 0.25 \\
\hline Group E & 0.09 & 0.56 & 0.76 & 0.75 & 0.37 & 0.26 \\
\hline Group F & 1.00 & 1.00 & 1.00 & 1.00 & 1.00 & 1.00 \\
\hline
\end{tabular}




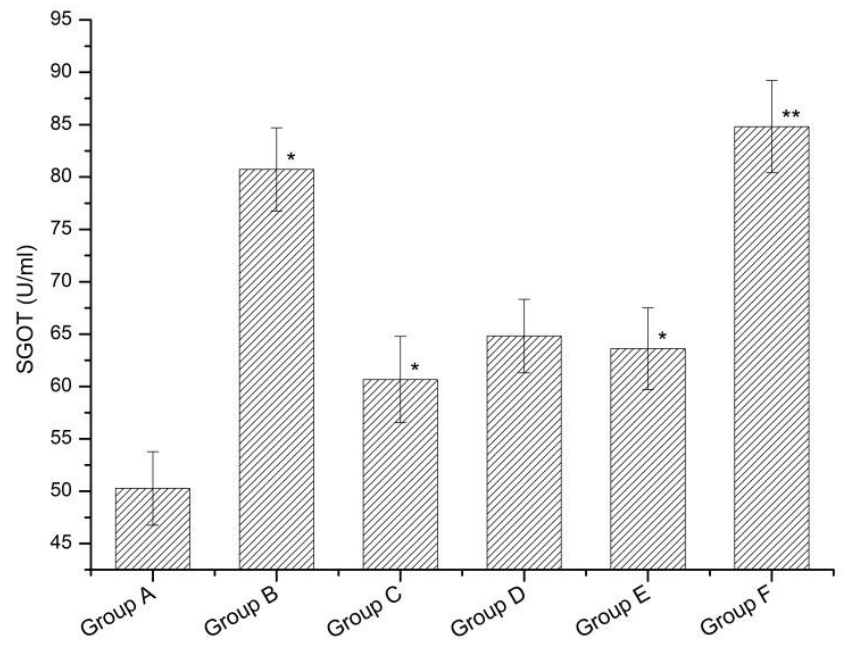

Fig. (4): The enzymatic levels of serum glutamic oxaloacetic transaminases (SGOT)

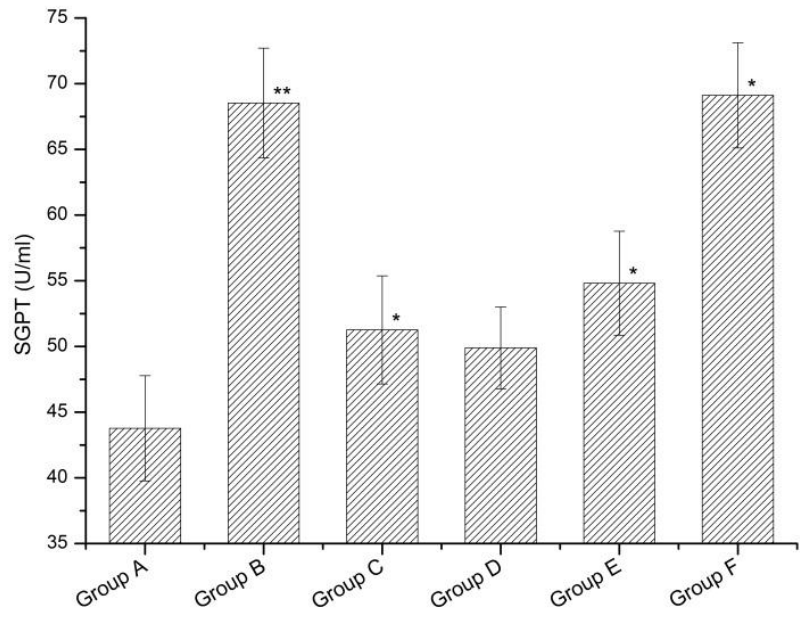

Fig. (5): The enzymatic levels of serum glutamic pyruvic transaminases (SGPT) 


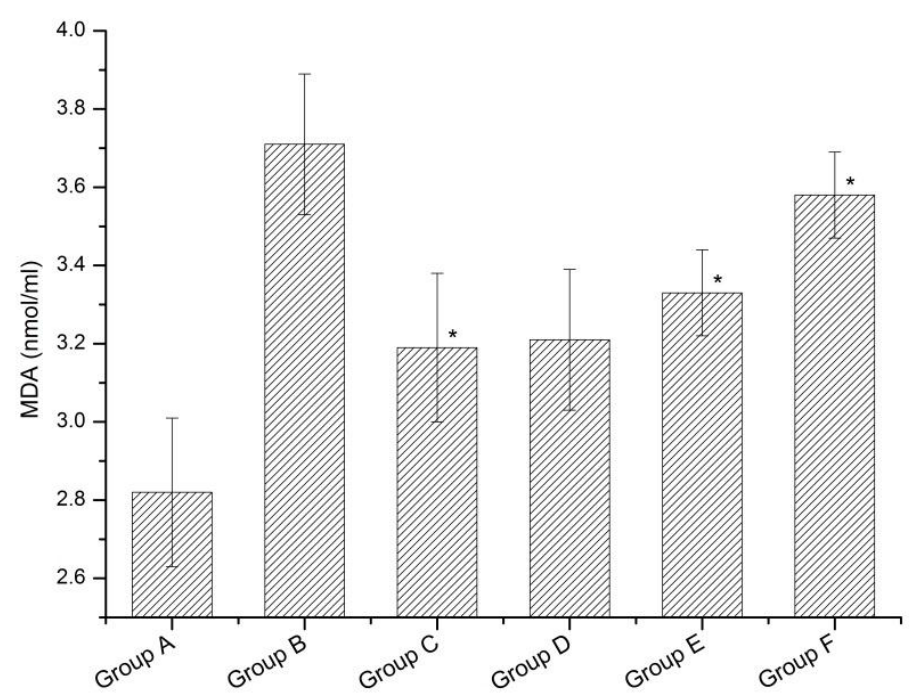

Fig. (7): The enzymatic levels of Malondialdehyde (MDA)

Table (4): A list of data for liver enzymes SGOT, SGPT, TP, and MDA from all groups

\begin{tabular}{lcccc}
\hline & $\begin{array}{c}\text { SGOT } \pm \text { S.D } \\
(\mathrm{U} / \mathrm{ml})\end{array}$ & $\begin{array}{c}\text { SGPT } \pm \text { S.D } \\
(\mathrm{U} / \mathrm{ml})\end{array}$ & $\begin{array}{c}\text { TP } \pm \text { S.D } \\
(\mathrm{gm} / \mathrm{dl})\end{array}$ & $\begin{array}{c}\text { MDA } \pm \text { S.D } \\
(\mathrm{nmol} / \mathrm{ml})\end{array}$ \\
\hline Group A & $\mathbf{5 0 . 2 7 \pm 3 . 5 1}$ & $43.77 \pm 4.01$ & $6.56 \pm 0.19$ & $2.82 \pm 0.19$ \\
Group B & $\mathbf{8 0 . 7 2 * \pm 3 . 9 8}$ & $68.53 * * \pm 4.18$ & $7.22 * \pm 0.18$ & $3.71 \pm 0.18$ \\
Group C & $60.66 * \pm 4.12$ & $51.26 * \pm 4.12$ & $6.78 * \pm 0.29$ & $3.19 * \pm 0.19$ \\
Group D & $64.82 \pm 3.51$ & $49.89 \pm 3.11$ & $6.58 \pm 0.18$ & $3.21 \pm 0.18$ \\
Group E & $63.61 * \pm 3.91$ & $54.81 * \pm 3.96$ & $6.76 * \pm 0.21$ & $3.33 * \pm 0.11$ \\
Group F & $\mathbf{8 4 . 8 1 * * \pm 4 . 4 1}$ & $69.11 * \pm 4.01$ & $7.72 \pm 0.21$ & $3.58 * \pm 0.11$ \\
\hline
\end{tabular}

* The difference is not significant (NS) $(\mathrm{p}>0.01)$

** The difference is significant $(\mathrm{S})(\mathrm{P}<0.05)$ 
Table (5): A list of RFD liver enzymes SGOT, SGPT, TP, and MDA from all groups

\begin{tabular}{ccccc}
\hline & SGOT & SGPT & TP & MDA \\
\hline Group B & 0.88 & 0.98 & 0.57 & 1.17 \\
Group C & 0.30 & 0.30 & 0.19 & 0.49 \\
Group D & 0.42 & 0.24 & 0.02 & 0.51 \\
Group E & 0.39 & 0.44 & 0.17 & 0.67 \\
Group F & 1.00 & 1.00 & 1.00 & 1.00 \\
\hline
\end{tabular}

\section{Conclusion}

The results suggested that exposure to such fields produced a significant biodamage and electrostructural changes in liver tissues. New recommendations for exposure to such fields should be demonstrated and further evaluations should be considered to highlight the possible hazardous effects on health. In the present study, exposure to magnetic fields should not be considered less important than high energy photons. A further work and a lot of research should be done and a further scientific activity and governmental concerns about these fields should be taken into account.

\section{REFERANCES}

1-Goodman R, et al. Electromagnetic fields and cells. Journal of cellular Biochemistry; 1993, 51: 436441.

2-Glaser, R.; Biophysics by Roland Glaser 4th edd. The mechanical properties of cell membrane. 2001, (C) Springer-Verlag Berlin Heidberg.

3-David O. C, and Sinerik A. biological effects of electric and magnetic fields sources and mechanisms, 1994, volume 1,(academic press, london, new york):105-177.

4-Dumanskii, Iu. D., et al.; Electric power transmission lines as a source of electromagnetic fields and the problem of environmental hygiene. 1981, Hygiene of residential areas, (20): 18-22.

5-Mai. I. El-kaliuoby, et al. Monitoring of relative changes in rats' tibia bone characteristics after exposure to $4 \mathrm{kv} / \mathrm{m}-50 \mathrm{~Hz}$ electric fields", International Journal of Current Research. 2017, 9, (12), 62026- 62031.
6-A. M. Khalil, et al. Monitoring of Variations in Some Hematological Parameters and Liver Enzymes as a Result of Exposure to 50-Hz Electric Fields J. Harmoniz. Res. Med. and Hlth. Sci. 2016, 3(2), 113-120.

7-Mai. I. El-Kaliuoby, et al. "Monitoring Of Rat's Blood Rheology after Exposure to 50-Hz Electric Fields (Occupational Study)" 2016, IOSRJESTFT. Vol.10, Iss.4 Ver. III, PP 04-08.

8-Berg, H., Electrostimulation of cell metabolism by low frequency electric and electromagnetic fields, Bioelectrochem. Bioenerg., 1993, 31, 1-25.

9-Duda, D., J. GRZESIK, K. PAWLICKI, Changes in liver and kidney concentration of copper, manganese, cobalt and iron in rats exposed to static and low-frequency $(50 \mathrm{~Hz})$ magnetic fields, J. Trace Elem. Electrolytes Health Dis., 1991, 15, 181-188.

10-Kula, B., M. Drozdz, A study of magnetic field effects on fibroblasts cultures, Part 2: The evaluation of effects of static and extremely low frequency (ELF) magnetic fields on free radical processes in fibroblasts cultures, Bioelectrochem. Bioenerg., 1996, 39, 27-30.

11-Murphy, J., D. Kadf, V.J. Warren, A. Sivak, Power frequency electric and magnetic fields. A review of genetic toxicology, Mutation Res., 1993, 296, 221-240.

12-Makowski, J., H. Oledzka-Slotwinski, B. GONET, Effect of constant magnetic field on rat hepatocytes, Annal. Med. Pol. Acad. Sci., 1976, 21, 78-81.

13-Parafiniuk, M., E. Gorczynska, A. Gutsch, W. Parafiniuk, Effect of constant magnetic field on the liver of guinea pig: Electron microscopic studies, Folia Histochem. Cytobiol., 1992, 30, 119-124.

14-Rollwitz, J., M. Lupke, M. Simko, Fifty-hertz magnetic fields induce free radical formation in mouse bone marrow-derived promonocytes and

Arab J. Nucl. Sci. \& Applic. Vol. 52, No.3 (2019) 
macrophages, Biochim. Biophys. Acta, 2004, 1674, 231-238.

15-Simko, M., M.O. Mattsson, Extremely low frequency electromagnetic fields as effectors of cellular responses in vitro, possible immune cell activation, J. Cell Biochem., 2004, 93, 83-92.

16-Till, U., C.R. Timmel, B. Brocklerhurst, P.J. Hore, The influence of very small magnetic fields on radical recombination reactions in the limit of slow recombination, Chem. Phys. Lett., 1998, 208, 7-14.

17-Becker, R.O, A.A. Marino, Electromagnetism and Life, Albany State University of New York, Suny Press, 1982, 24.

18-Frohlich, H., The biological effects of microwaves and related questions, $A d v$. Electronics and Electron Phys., 1980, 53, 85-152.

19-Ahmed. M. El-Khatib, et al. Effects of $50-\mathrm{Hz}$ magnetic field on some biophysical properties of Albino Rat's blood. American Journal of Research Communication, 2016, 4(6): 126-139.

20-Fischbach, F., B. Zawta, Age-dependent reference limits of several enzymes in plasma at different measurement temperatures, Klin. Lab., 1992, 38, 555-561

21-Henery, R.J., Clinical chemistry, Harper and Row Publishers, New York, 1964.

22-G. Turgut et al. Changes in the levels of MDA and GSH in mice serum, liver and spleen after aluminum administration, 2006 Eastern Journal of Medicine: 11:7-12

23-Charles Polk and Elliot Postow. Handbook of Biological Effects of Electromagnetic Fields, part I, 1995, Published by CRC Press, ISBN 10: 0849306418.

24-Nathwani RA, Pais S, Reynolds TB, Kaplowitz N, Serum alanine aminotransferase in skeletal muscle diseases. 2005, Hepatology 41: 380-382.

25-Ozer J, Ratner M, Shaw M, Bailey W, Schomaker $\mathrm{S}$, et al. The current state of serum biomarkers of hepatotoxicity. 2008, Toxicology 245: 194-205.

26-Dufour DR, Lott JA, Nolte FS, Gretch DR, Koff $\mathrm{RS}$, et al. Diagnosis and monitoring of hepatic injury: I. Performance characteristics of laboratory tests. 2000, Clin Chem 46: 2027-2049.

27-Dufour DR, Lott JA, Nolte FS, Gretch DR, Koff $\mathrm{RS}$, et al. Diagnosis and monitoring of hepatic injury: II. Recommendations for use of laboratory tests in screening, diagnosis and monitoring. 2000, Clin Chem 46: 2050-2068.

28-Amacher DE, A toxicologist's guide to biomarkers of hepatic response. 2002, Hum Exp Toxicol 21: 253-262.

29-Zieve L, Anderson W, Dozeman R, Draves K, Lyftogt C, Acetaminophen liver injury: Sequential changes in two biochemical indices of regeneration and their relationship to histologic alterations. 1985, J Lab Clin Med 105: 619-624.
30-Korsrud GO, Grice HC, McLaughlan JM, Sensitivity of several serum enzymes in detecting carbon tetrachloride-induced liver damage in rats. 1972, Toxicol App Pharmacol 22: 474-483.

31-Kawai M, Hosaki S, Clinical usefulness of malate dehydrogenase and its mitochondrial isoenzyme in comparison with aspartate aminotransferase and its mitochondrial isoenzyme in sera of patients with liver disease. 1990, Clin Biochem 23: 327-334. 